\title{
Tentativas de desconstrução do racismo e preconceitos: um diálogo entre o Norte e o Sul do no século XXI
}

\author{
Racisme and Prejudice deconstruct attempts: a \\ dialogue between North and Soyth in the XXI century
}

\begin{abstract}
En train de déconstruire le racisme et des préjugés: un dialogue entre le Nord et le Sud dans le XXI siècle
\end{abstract}

Nilce da SILVA

\begin{abstract}
RESUMO
Este artigo apresenta tentativas de desconstrução do racismo implementadas pelo Brasil e pelo Canadá. Quanto a esse país, aborda-se ação realizada na Faculdade de Educação da Universidade de São Paulo embasada na Lei 10639/03 e apoiada pelo CNPq no âmbito do Edital ProAfrica. Quanto ao Canadá, apontamos a Lei de Quebec, a Révolution tranquille; a Charter of Rights and Freedoms e os accommodements raisonnables como indicadores do movimento cotidiano que a sociedade quebequense faz no sentido de desconstruir diferentes formas de racismo, tal como podemos observar na constituição e existência de escolas dé diferentes etnias, grupos sociais, religiosos, como, por exemplo, a Éscola Portuguesa em Montreal.

Finalmente, considera-se que a destruição do racismo e do preconceito são processos tão Tongos como a construção dos mesmos e são colocados em funcionamento nas sociedades estudadas caracterizadas pela recepção de imigrantes.
\end{abstract} escola

Palavras- chave: Canadá; Brasil; desconstrução do racismo; leis;

\begin{abstract}
This article has attempted to racism deconstruction political implemented by Brazil and Canada. As for this country, it approaches action held at the Faculty of Education, University of Sao Paulo, based on Law 10639/03 and supported by CNPq under ProAfrica Public proposal.
\end{abstract}


Regarding Canada, pointed out the Law of Quebec, the 'Révolution tranquille', the Charter of Rights and Freedoms and the 'accommodements raisonnables' as daily indicators movement that Quebec society is doing to deconstruct the different forms of racism, as we observe the constitution and existence of schools of different ethnic groups, social groups, religious, for example, the Portuguese School in Montreal.

Finally, it is considered that the destruction of racism and prejudice are processes so long as their construction and this destruction is put into operation in Brazilian and Canadian societies characterized by immigrant reception.

Index terms: Canada, Brazil; deconstruction of racism, laws, school.

\section{RÉSUMÉ}

Cet article montre les actions pour la déconstruction du racisme mises en œuvre par le Brésil et par le Canada. En ce qui concerne la realité bresilienne, nous parlerons d'action tenue à la Faculté d' éducation de l'Université de Sao Paulo, basée sur la loi 10639/03 et soutenu par le CNPq en vertu de l'affiche PROAFRICA. En ce qui concerne le Canada, nous avons souligné la Loi du Québec, la Révolution tranquille, la Charte des droits et libertés et les accommodements raisonnables comme indicateurs du mouvement quotidien que la société québécoise fait de déconstruire les différentes formes de racisme, comme nous avons observé av̀ec la constitution et l'existence d'écoles de différents groupes ethniques, groupes sociaux, religieux, par exemple, l'École portugaise à Montréal.

Enfïn, il est considéré que la destruction du racisme et des préjugés sont des processus aussi long que leur construction et leur mise en fonctionnement dans des sociétés caractérisées par l'accueil des immigrants comme le Brésil et le Canada.

Mots clés: Canada, Brésil; déconstruction du racisme; lois; école. 


\section{Introdução}

Este artigo apresenta tentativas de desconstrução do racismo implementadas no Brasil e no Canadá.

Fruto da Lei 10639/03, apresentamos neste artigo, na parte intitulada 'O SUL', pesquisas realizadas em Moçambique apoiadas pelo edital ProAfrica fase 1 e fase 2 e, neste contexto, da fundação da Revista Acolhendo a Alfabetização nos Países de Língua Oficial Portuguesa. Apresentaremos a pesquisa- ação junto a alunos do curso de Pedagogia da Universidade de São Paulo (USP) por meio da docência da disciplina optativa que criamos intitulada 'Metodologia e Fundamentos da Alfabetização em Países de Língua Oficial Portuguesa (PALOPs): uma introdução', ministrada, para fins deste trabalho, no primeiro semestre de 2008, por meio da qual, fizemos transposição didática do conteúdo estudado junto a, aproximadamente, 800 alunos do Ensino Fundamental.

Por meio destes processos investigativos, conseguimos entender a natureza da colonização portuguesa em Moçambique, a problemática da escolha da língua portuguesa como língua oficial do país, a constituiçẫo do mesmo enquanto nação, a importância da escola para os moçambicanos, as relações estabelecidas entre esta nação e o Brasil e, ainda, destes países com os do hemisfério Norte; e, finalmente, concluímos que a Lei 10639/03, toda a discussão que ela aporta e as ações após sua implantação se constituem em medida, de fato, de luta contra o racismo.

Em seguida, na parte intitulada O Norte, já que estivemos imersos na francofonia no ano de 2008 e 2009, apresentaremos algumas considerações acerca do Canadá, mais especificamente do Quebec, enquanto sociedade que luta cotidianamente contra as diferentes manifestações do racismo em seu território especialmente porque se constitui como local de recepção de 
imigrantes promovidas pela Lei de Quebec, pela Révolution tranquille, pela Charter of Rights and Freedoms e pelos accommodements raisonnables; já que indicam o movimento cotidiano da sociedade quebequense faz no sentido de desconstruir diferentes formas de racismo, tal como observamos na constituição e existência de escolas de diferentes etnias, grupos sociais, religiosos, tal como a escola portuguesa em Montreal.

Finalmente, consideramos que a destruição do racismo e do preconceito são processos tão longos como a construção dos mesmos e a escola pode contribuir para perpetuar estes processos desumanos ou para destruí-los.

\section{O SUL}

A Lei 10639/03 veio ao encontro das nossas expectativas. Pôr isso, no ano de 2004, quando da abertura do edital do CNPq PROÁFRICA, estabelecemos os primeiros contatos com Moçambique e elaboramos o projeto de pesquisa intitulado 'Via Atlântica: perspectivas fraternas na Educação de Jovens e Adultos entre Brasil e Moçambique'. Nestes primeiros dois anos de trabalho (2004- 2006), pudemos construir víneulos neste país, visitá-lo, conversar com professores da Universidade Eduardo Modlane (UEM) e receber estes colegas em nossa Universidade.

Assim, no âmbito do Edital 06/2007 - PROÁFRICA - Chamada 2: apoio financeiro a atividades de cooperação internacional para a execução de projetos conjuntos, tivemos aprovada concessão de auxílio financeiro à pesquisa para apoio ao seguinte projeto de pesquisa: 'Resgate da memória social e o papel da Revista Acolhendo a Alfabetização nos Países de Língua Portuguesa (Revista Acolhendo) como suporte prático-teórico em favor da Lei 10639/03'. A partir deste projeto, um processo de pesquisa- ação foi instaurada pela apresentação de disciplina em nível de graduação em que, 
juntamente com os alunos, realizamos transposição didática (CHEVALLARD, 1991) de conteúdo sobre culturas afro-brasileiras junto a salas de aula de Educação Infantil, Ensino Fundamental e Educação de Jovens e Adultos em escola públicas e privadas da cidade de São Paulo.

Os conceitos de colonização, lusofonia, cultura, etnia, língua materna, língua oficial, língua veicular, identidade, fracasso escolar, resistência à aprendizagem da língua, entre outros, foram importantes neste contexto de ensino e de aprendizagem.

O conteúdo tratado na disciplina foi o seguinte:

a) Aspectos gerais da colonização portuguesa; um panorama acerca dos processos de libertação dos PALOPs.

b) A relação entre língua materna e a alfabetização em língua portuguesa.

c) O 'mundo oficial lusófono' e as parecerias de colaboração bí (multi) laterais. d) Bilinguismo/ multilinguismo / multiculturalismo ou policulturalismo: o ensino e a aprendizagem da língua pertưguesa, a resistênciàà língua oficial.

e) A relação entre linguagem e identidade;

f) Moçambique: um estudo de caso.

d) Alfabetização bi (multi) lingue.

e) A Lei 10.639 de 2003 e a formação de alfabetizadores.

Durante a regência deste curso em que ensinávamos sobre a lusofonia formamos dois 'espaços de criação'. Tais 'espaços' funcionaram 
durante o primeiro semestre de 2008 pelo período de 30 horas cada um. Nestes locais, professores da rede pública e particular da cidade de São Paulo e alunos da Faculdade de Educação da USP estudaram as principais características do mundo lusófono e, depois deste estudo, por meio de transposição didática, eles ensinaram o que aprenderam comigo a alunos da Educação Infantil, Básica (regular e Educação de Jovens e Adultos) em escolas públicas e privadas da cidade de São Paulo, também pela constituição de 'espaços de criação'.

Tais 'espaços' ofereceram subsídios práticos e teóricos para a viabilidade de Lei 10639/03 que altera Lei 9394/96 de Diretrizes e Bases da Educação Nacional e estabelece obrigatoriedade do Ensino de História e Cultura Afro-Brasileira e Africana na Educação Básica e o Parecer No $1 / 04$ do CNE que estabelece as Diretrizes Curriculares das Relações ÉtnicoRaciais.

Os dois 'espaços de criação' formados, aqui designados como A e B, eram formados, em março de 2008 , da seguinte maneira:

\section{ESPAÇO A}

32 mulheres e dois homens

28 pessoas abaixo de 30 anos; seis pessoas acima de 30 anos

Oito pessoas com renda média familiar abaixo de cinco salários mínimos, e os demais, acima desta faixa.

\section{ESPAÇO B}

22 mulheres e três homens 
19 pessoas abaixo de 30 anos; seis pessoas acima desta idade.

Cinco pessoas com renda familiar mensal até cinco salários mínimos, e os demais, acima desta faixa.

Os usuários dos referidos 'espaços de criação' colaboraram conosco na realização deste projeto, pois levaram para muitas salas de aulas os temas estudados no âmbito dos referidos espaços de formação e trouxeram suas impressões para discussão em grupo de professores e futuros professores.

Por meio de questionário aplicado junto aos nossos colaboradores obtivemos que:

- Os usuários dos respectivos locais atingiram, em torno de, 800 crianças que passaram a conhecer aspectos do mundo lusófono. Destas 800 crianças, $99 \%$ se mostraram satisfeitas durante o ensino de aspectos das culturas afro-brasileira e africanas dos PALOPs.

- $80 \%$ das crianças atendidas eram alunos de escolas públicas da cidade de São Paulo.

- Em torno de $85 \%$ das crianças atendidas m̧ostraram não conhecer o assunto tratado em sala de aula por nossos colaboradores.

- Uma pequena porcentagem, em torno de 5\%, das escolas convidadas para participarem desta pesquisa-ação não permitiu que assuntos referentes ao continente africano fossem abordados em suas instituições. Todas eram escolas particulares cuja clientela era de classe média- alta.

— $85 \%$ dos nossos colaboradores entendiam que as 'transposições didáticas' - que duravam, em média, de duas a três horas em sala de aula- realizadas poderiam se transformar em um curso, com 
mais tempo de estudo, acerca das culturas afro-brasileiras e africanas para as crianças atendidas.

- Do conteúdo estudado nos 'espaços de criação', as seguintes palavras- chave foram utilizadas tanto nos planejamentos de aula como nas transposições didáticas em si, sendo que as apresentamos abaixo das usadas mais frequentemente, para as menos usadas : África- Brasil- Portugal- Colonização, escravo, língua portuguesa, lusofonia- negro- pobreza- cultura, identidade, etnia, grupos linguísticos- preconceito, racismoalfabetização, literatura- Moçambique, multiculturalismo, policulturalismo- preto, pardo, mulato, selvagem- língua materna- Angola- Guiné- Bissau- Timor- Leste- Cabo VerdeMacau, Goa, São Tomé e Príncipe- latino, cucarachadiversidade, respeito, igualdade- criolo, negão, neguinha, cor de pele, pele cor-de-rosa, região Norte e Nordeste do Brâsil, animais, divisões políticas- analfabetismo, guerra civil, moreno, branquela, macaco (gente), outras.

Constatou-se a necessidade e a viabilidade do exercício da transposição didática nestes contextos educacionais.

Em suma, no caso desta experiência no Brasil, afirmamos que a mesma se constituiu como um processo de desconstrução do racismo na sociedade brasileira na medida em que criamos condições para que nossos alunos ${ }^{1}$, sujeitos desta pesquisa, investigassem e discutissem: questões relativas ao processo de alfabetização em língua portuguesa nas antigas colônias de Portugal, especialmente, Moçambique, enfocando a relação

\footnotetext{
${ }^{1}$ Nos Cadernos de Pedagogia da UNIFEO, neste ano, será publicado artigo da mesma autora intitulado Espaços de criação e a ética do cuidado na alfabetização: pesquisa- ação na cidade de São Paulo a favor da Lei 10.639 de 2003 no qual se esclarece as possibilidades da desconstrução de práticas racistas à luz da ética do cuidado de D. W. Winnicott. Para os interessados, recomenda-se também a participação ao Congresso Internacional sobre a Ética do Cuidado, PUC- São Paulo, maio deste ano.
} 
entre 'língua materna' do educando e a citada língua oficial, questão relevante no âmbito do ensino e da aprendizagem nestes países; refletissem sobre a realidade do 'mundo oficial lusófono', buscando as relações e implicações dos fundamentos teóricos estudados para a construção de uma visão crítica referente à importância do papel do professor alfabetizador nestas sociedades tendo em vista os semelhantes processos coloniais; programassem e executassem atividades que o preparassem para atuar como docente, ou ainda, em diferentes postos da área educacional nacional e internacional que tratassem das relações de cooperação Brasil e demais PALOPs, tanto em instituições governamentais propriamente ditas como em não-governamentais; obtivessem subsídios para atuar em diferentes posições do sistema educacional brasileiro.

\section{O NORTE}

Apesar de toda a inserção no Hemisfério Sul, tanto no plano acadêmico como profissional, o Norte nos atraía. Foi assim, magnetizados pelo polo Norte, que no ano de 2006, postulamos e obtivemos bolsa junto aó governo canadense, Bourse de recherche en études canadiennes (BREC), por meio da qual iniciamos trabalho de pesquisa no Canadá. Constatamos que o direito da transmissão e manutenção da língua portugúesa é percebido com a existência e funcionamento de escola portuguesa em Montreal; assim como, outras escolas, de outras nacionalidades, de grupos sociais, grupos religiosos também têm o direito de funcionar no Canadá. Atribuímos tal fato às seguintes conquistas: Lei de Quebec, a Révolution tranquille, a Charter of Rights and Freedoms e a política dos accommodements raisonnables.

O Canadá é o segundo maior país do mundo em extensão. Localizase no extremo norte da América do Norte. É banhado por três oceanos: Atlântico, Pacífico e o Ártico. Ocupa o quarto melhor lugar quando medido o Índice de Desenvolvimento Humano (IDH). Possui em torno de 32 
milhões de habitantes. Em 2002, teve US\$ 714,3 bilhões de Produto Interno Bruto (PIB), portanto US\$22.321,00 de renda per capita anual (CATTANI, 2006).

Como sabemos, franceses e ingleses são os dois povos fundadores do Canadá, que é, após inúmeros debates em diferentes planos políticos, um país oficialmente bilíngue. A característica do francês no Canadá é sua concentração geográfica nas seguintes regiões: Québec, Nouveau Brunswick ${ }^{2}$, Ontario, Manitoba, Île du Prince Édouard e Nouvelle Écosse.

O Canadá foi colonizado até o século XVIII pela França, e depois, o Reino Unido começa a controlar o país. Durante oitenta anos, troppas francesas e inglesas disputaram o território, apesar de, em 1763, um tratado de paz reconhecer o controle do Reino Unido sobre o país. Entretanto, pela Lei de Quebec, de 1774, os colonos franceses têm a permissão de manter sua língua e costumes. Apenas em 1931, ocorre o fim da subordinação do Parlamento canadense à Inglaterra e a separação 'completa' desse país.

Um quarto da população, notadamente na província de Quebec, tem o francês como língua materna, ainda que haja uma minoria pumérica linguística_anglófona com maior poder aquisitivo. Em outras regiões do país, os francófonos formam a minoria. E, ao mesmo tempo, o Canadá tem cidadãos com línguas maternas diferentes de ambas, tendo em vista a imigração dos últimos 40 anos.

No Quebec, especialmente porque foi o palco da Révolution tranquille $^{3}$, condena-se toda forma de desrespeito ao outro e de discriminação; atitudes que podem ser fortemente penalizadas. Para tanto,

\footnotetext{
${ }^{2}$ Única província oficialmente bilíngue do país.

3 A Révolution tranquille ocorreu no Quebec entre 1960, 1970, promovendo diferentes mudanças na sociedade quebequense que reclamava sua identidade como francófona. Neste período, os franco-canadenses, os falantes do francês, se autodenomiram: québécois. Houve grande investimento no sistema de ensino público, criação de um ministério da educação; organização dos sindicatos no âmbito da função pública; dentre outras medidas. A sociedade rejeitou valores religiosos do catolicismo para fundar uma sociedade laica, de direito.
} 
há todos os tipos de comisssões que defendem os direitos das pessoas: de homossexuais, de mulheres, de negros etc.

Na mesma direção, há que se destacar a noção jurídica associada ao mundo do trabalho com o objetivo criar normas para que se evite a discriminação neste meio, assim como em toda a sociedade. Ou seja, a sociedade quebequense procura combater o próprio racismo, talvez, também porque é vítima do fenômeno.

Vejamos a situação da lusofonia, mais especificamente de portugueses e brasileiros neste contexto.

Ao consultar dados do Censo Canadense de 1996, Teixeira (2000), temos que o grupo português era numericamente um dos grupos étnicos mais importantes do Canadá (335.110 pessoas). Nesta direção, ainda afirmam que o português também era frequentemente um dos idiomas nãooficiais mais informados como língua materna, classificando-se em terceiro depois do chinês (286.460 pessoas) e do italiano (202.440 pessoas). E, finalmente, os autores destacam que líderes da comunidade portuguesa, inclusive autoridades portuguesas no Canadá, afirmam que o número de canadenses portugueses (primeira, segunda e terceiras geraçẫes) varia entre 400 mil e 550 mil pessoas. Segundo Teixeira e da Rosa (2000), tal fluxo deve-se ao fato do Canadá ter experimentado rápida mudança, especialmente na segunda metade do século XX, quando se tornou, de fato, um país de atração. A imigração, neste sentido, transformou a geografia social de inúmeras cidades canadenses, dentre elas, destacamos, a cidade de Montreal.

A constituição da cidade de Montreal, apoiada pela política canadense de imigração, é um mosaico de bairros étnicos. Em Saint Louis (leste de Mont Royal), os imigrantes lusófonos, por meio de laços de 
parentesco e amizade, tentam manter viva a língua e a cultura de origem. Um dos empreendimentos marcantes desta comunidade foi, apesar das limitações, o estabelecimento de escolas na cidade de Montreal, em 6 de novembro de 1971, Escola Portuguesa de Santa Cruz e, quatro anos mais tarde, era a vez da Escola Secundária Lusitana (EUSÉBIO, 2001).

No caso dos brasileiros instalados no Quebec, a maior parte deles chega à província na qualidade de imigrante qualificado e encontram dificuldades de diferentes natureza (inserção profissional, aprendizado da língua, equilíbrio emocional) conforme nos indicou um grupo de 14 brasileiros instalados nesta região, nos primeiros anos vividos na referida região a partir do ano 2000.

Os dados coletados ${ }^{4}$ nesta pesquisa exploratória apontam que a inserção no mercado de trabalho ocorre mais facilmente para os profissionais da área de exatas. Os profissionais ligados à área da saúde estão desempregados, apesar de terem feito os procedimentos legais pedidos pelo Ministério da Educação e Lazer do Quebec para validarem seus estudos. Mesmo com estudos validados e estágios na área realizados em terras canadenses, a inserção profissional não aconteceu até o-momento. E, finalmente, os imigrantes qualificados da área de humanas se encontram à margem do mercado profissional para o qual se prepararam no sistema escolar brasileiro e, segundo seus depoimentos, estão realmente decepcionados, pois esperavam encontrar trabalho em atividades para as quais estão preparados e com remuneração acima da recebida nos seus respectivos estados brasileiros.

Em resumo, no Quebec, especialmente porque foi o palco da Révolution tranquille, como já dissemos, apesar das dificuldades da

\footnotetext{
${ }^{4}$ Para maiores informações sobre esta pesquisa, consular Revista Millenium do Instituto Técnico de Viseu, final do ano de 2010 e começo do ano de 2011.
} 
comunidade portuguesa, as escolas analisadas funcionam há mais te 30 anos, ainda que com tensões, advindas dos seus preconceitos e processos de desconstrução dos mesmos, e a escola é importante neste contexto num local caracterizado pela recepção de imigrantes.

Entretanto, há se que ressaltar no âmbito destas sociedades conhecidas por serem 'multiculturais', a afirmação de Bhabha (in SANTOS, 2005, p. 237) nos adverte que

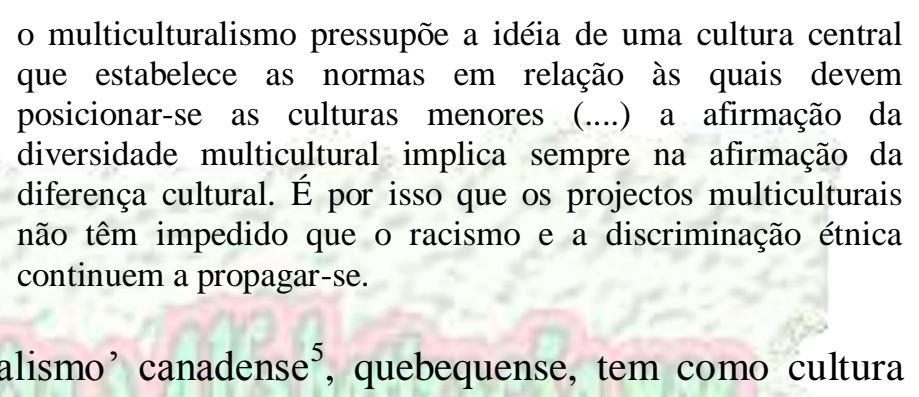
central a cultura inglesa (HELLY, 1996; CORMIER, 2005; RIFFEL e LEVIN, 2006). É esta, a cultura da anglofonia, que estabelece as normas para que as demais gravitem em torno dela, a saber: a cultura francófona (dá região do Quebec, por exemplo), das Primeiras Nações (verdadeiros donos do território americano antes da chegada dos colonizadores); e ainda, as culturas lusófona, árabe, dentre outras.

Entretanto, de acordo com estudiosos da questão do uso das duas línguas pelos canadenses (CATTANI, 2006; CORMIER, 2005; KANOUTÉ, 2002; ELBAZ, 2000), nos últimos 40 anos, tem ocorrido um processo de diminuição dos falantes de língua francesa. Os três motivos dessa redução são: 1. a queda da taxa de natalidade entre os francófonos em relação aos falantes do inglês a partir de 1971;2. imigrantes anglófonos que chegam com frequência ao Canadá. 3- A perda de imigrantes que se dirigem da francofonia para as províncias anglófonas.

${ }^{5}$ E ainda acrescentamos: o brasileiro. 
Dispersos sobre o vasto território canadense, muitas vezes, reagrupados em pequenas comunidades rurais isoladas, os francófonos minoritários, ainda que numerosos, sofrem de fraca densidade demográfica. Assim repartidos, as comunidades e os indivíduos recebem inegavelmente uma grande influência da língua e da cultura majoritária (CORMIER ${ }^{6}, 2005$, p. 3).

\section{Considerações finais}

No Canadá, a educação básica (11 anos de escolaridade) é de responsabilidade das províncias. Não existe nenhum departamento em nível federal. E, tal qual o Brasil, a questão da identidade é de suma importância na história do país.

Segundo Fasal Kanouté (2002), existem inúmeros processos de construção identitária das pessoas em situação de migração, ou ainda, de aculturação e, de acordo com Catanni (2006), a maior parte desses imigrantes não tem nem o francês nem o inglês como língua materna. Eles nunca se tornariam verdadeiros canadenses, porém, os seus filhos teriảm a oportunidade de, por meio do sistema público de ensino e a mistura-entre os canadenses, tornar-se verdadeiros cidadãos canadenses.

À luz dos estudos de Wallerstein $(1987,1988,2001,2002 \mathrm{a}, 2002 \mathrm{~b})^{7}$, podemos considerar o Canadá, tal como o Brasil (SANTOS, 2005), uma 'semi-colônia', pois não faz parte da pobreza mundial ao mesmo tempo em que é influenciado de muito perto pela cultura norte- americana, em

\footnotetext{
${ }^{6}$ Quando viemos ao Canadá pela primeira vez com bolsa do governo deste país, visitamos a Université de Moncton na província de Nouveau Brunswick. Lá, conhecemos a professora Cormier. Ela sempre afirmava que os franceses no Canadá formavam a minoria mais privilegiada do mundo, entretanto, muito deveria ser feito para assegurar o pleno direito à francofonia.

${ }^{7}$ Para maiores detalhes sobre estas afirmações, consulte os GRUPO DE TRABALHO - GT 34 do Congresso Luso- Afro Brasileiro de Ciências Sócias, Salvador, agosto, 2011, intitulado: Conhecimento, Cidadania e Identidade- organizado por Nilce da Silva e Isabel E. Carvalhais- mais especificamente, o trabalho de SILVA: A identidade do imigrantes de origem lusófona relacionada com o brain circulation
} 
diferentes áreas- da pesquisa ${ }^{8}$ aos pequenos atos do cotidiano- e, dentro de si mesmo, abriga o Quebec, francês de base e, portanto, é palco da tensão entre anglofonia- ainda colonizadora e, no passado, a vencedora das Plaines d'Abraham ${ }^{9}$, e francofonia.

O aprendizado das línguas oficiais- inglesa e francesa, segundo Cattani (2006), Cormier (2005) e Kanouté (2002), e dos seus valores simbólicos aliados às religiões protestante e católica, respectivamente, foi protegido pela constituição no então novo país desde 1867. Apesar disso, segundo os citados autores, na prática, os direitos constitucionais das minorias linguísticas não têm sido respeitados no Canadá como um todo. Eles nos dizem que a comunidade anglófona, economicamente poderosa, tem se desenvolvido na região do Quebec, criado e mantido suas escolas em língua inglesa com financiamento público desta província inclusive. Da mesma forma ocorre em New Brunswick, com uma substancial minoria falante do francês. No Canadá francês, as escolas não são afortunadas. Manitoba, por exemplo, eliminou as escolas católicas em 1890 e, apenas nos úlịmos 20 anos, as escolas puderam oferecer essa língua novamente.

A mudança de postura frente às respectivas minorias ganhou espaço em 1982-na nova constituição do país, com o Charter of Rights and Freedoms, pelo menos nas escolas públicas, inclusive porque passa a garantir escolas com o ensino em francês para alunos com raízes na francofonia e com língua materna francesa. Por isso, a situação dos anglófonos no Quebec hoje é menos satisfatória do que já foi e o Quebec respeita, e mesmo promove, a diversidade de culturas na província.

\footnotetext{
8 Ver a parte 3.2 desta tese em que apresentamos pesquisa quantitativa que desenvolvemos junto com pesquisadores canadenses. Há que se notar a forte influência americana no trabalho, facilmente percebida ao examinarmos a bibliografia utilizada no processo.

${ }^{9}$ Local na cidade do Quebec em que ingleses e franceses se enfrentaram pela hegemonia do território canadense. Em 1759, a Inglaterra vence a França nesse processo.
} 
A análise da distribuição do capital linguístico, tanto na cidade de São Paulo, quanto no Canadá ${ }^{10}$ como um todo, pode exemplificar como é possível se realizar essa ideia de Bourdieu (1980, 1998, 2001), Bourdieu e Passeron (1964) e Bourdieu e Champagne (1980) sobre os simulacros, ou seja, a frequência à escola universalizou-se, mas o domínio da leitura e da escrita, componentes importantíssimos em qualquer sistema educacional ocidental, não é oferecido de fato aos alunos. Assim, do nosso ponto de vista, a questão das minorias linguísticas é assunto importante para as duas realidades, tendo em vista a pluralidade étnica que compõe os dois países em questão e a escola de segunda categoria que é oferecida às mesmas.

No Canadá, de acordo com Cormier (2005), muitos alunos do meio minoritário canadense sofrem de insegurança linguística, sendo vítimas da falta de escola francófonas no lugar onde moram ou frequentando escolas inferiores quando comparadas com as da anglofonia ${ }^{11}$. Tal insegurança se manifesta quando as pessoas se sentem incapazes de falar bem a sua língua e acabam por construir uma baixa autoestima e, finalmente, apresentam dificuldades de aprendizagem na escola. Ou seja, diferentes línguas, com variedades dialetais, que marcam diferenças relevantes se considerarmos o acesso aos bens culturais relacionados ao capital linguístico de cada um dos países em pauta.

Nesta direção, também concordamos com Pierre Bourdieu (1980) quando ele explicita a existência de racismos no mesmo número de grupos que têm a necessidade de se justificarem sobre outros. E assim, quantas

\footnotetext{
${ }^{10}$ Com relação à exclusão feita pelo Quebec aos estudos feitos pelos imigrantes brasileiros no sistema educacional do Brasil, recomendamos a leitura do capitulo 2.3, parte II desta tese.

${ }^{11}$ O Ensino Secundário em língua francesa (dos 14 aos 17 alunos para alunos em idade padrão de escolarização) na região do Quebec é dividido em vários programas. Dentre eles, há o Programa de Música que, do nosso ponto de vista, oferece ampla formação aos adolescentes. Este, além das disciplinas básicas do currículo, tem aulas de teoria e prática musical, participando de bandas, orquestras e corais. Os alunos estudam dois instrumentos musicais. O período escolar é integral. Ou seja, cada equipamento escolar atende apenas a um período de estudos por dia. Para ter acesso ao programa, o aluno gasta, em média, 600 reais por mês, sendo que, toda criança no Canadá recebe quantia equivalente por meio de programas governamentais que têm por objetivo assegurar vida digna na infância e na adolescência.
} 
forem as colonizações sofridas por uma população, quantos forem os grupos de imigrantes recebidos, também portadores das suas respectivas colonizações, tantos serão os racismos constatados.

Apesar do discurso do governo canadense ser da construção do multiculturalismo, sabemos que esta palavra comporta uma nova configuração, chamada por Pierre-André Taguieff de neo-racismo.

Com estes novos conceitos passamos do uso da palavra raça à cultura, com a substituição da ideia de pureza racial pela de identidade cultural autêntica; da desigualdade à diferença, em que o desprezo pelos 'inferiores' dá lugar à obsessão do contacto com eles; recurso a enunciados mais heterófilos do que heterófobos, ou seja, à insistência no direito à diferença da maioria face às culturas minoritárias; é uma expressão simbólica e indirecta, mais do que directa e assumida (TAGUIEFF in MACHADO, 2000, p. 6). ${ }^{12}$

\section{Segundo van Dijk (DIJK in MACHADO, 2000), tanto os EUA como} os países europeus ocidentais receptores de imigrantes constituem, acima de tudo, sociedades de dominação racial, em que um grupo maioritário branco domina, a todos os níveis da existência coletiva, uma ou mais minorias étnicas e raciais totalmente subordinadas. Nesse quadro, "o preconceito não é apenas uma atitude individual de certas pessoas (preconceituosas), mas uma forma de cognição social estruturalmente fundada" (DIJK, 1987, p. 391 in MACHADO, 2000) que é destinada a legitimar essas relações de dominação global e que conhece uma reprodução alargada através de todo o tipo de discursos. Estruturas de poder e dominação, cognição social e discurso constituem, por outras palavras, o modelo articulado que o autor adota para analisar o racismo (Cf. DIJK in MACHADO, 2000). Tanto o racismo flagrante como o sutil- este último reconhecido também como predominante- permeia, em sentido descendente, “[....] todos os níveis

\footnotetext{
${ }^{12} \mathrm{Na}$ cidade de Trois-Rivières, em uma de suas salas de espetáculo, a sala Antonio- Thompson, existe uma programação semanal intitulada Les Grands Explorateurs. Aos sábados à noite, um conferencista apresenta um país, uma cidade, uma região. A escolha do local parece se basear no 'exotismo'. Ao seguirmos a programação desta série de palestras, soubemos que o Brasil é um dos locais apresentados.
} 
sociais e pessoais das nossas sociedades: desde as decisões, ações e discursos dos corpos legislativos e governamentais, passando pelos de várias instituições, na educação, investigação, media, saúde, polícia, tribunais e agências sociais, até à conversação, pensamento e interação quotidianos" (DIJK in MACHADO, 2000, p. 9).

Segundo os dados que coletamos e levando em consideração o nosso processo de inserção na sociedade quebequense, consideramos que a interação social quotidiana entre brasileiros e quebequenses dá espaço a processo cruzado de categorização, fundado na própria visibilidade imediata dessa diferença: o quebequense 'rejeita' o brasileiro por ele ser brasileiro ao mesmo tempo em que dele se aproxima por falar uma língua latina que é portadora de uma história parecida com a sua. Entretanto, o brasileiro, que foi 'rejeitado' e não se esqueceu, olha para o quebequense como um ser inferior e provinciano, que não conseguiu se tornar independente da colonização inglesa. Assim, frente ao francófono, o brasileiro faz uso de suas competências americanizadas e se sobrepõe. Entretanto, frente ao anglófono, o brasileiro, outra vez, se retrai.

Entretanto, caso seja possível fazer uma escala de graus de racismo, pode ser que o racismo no Quebec, se comparado com oútras nações do mundo, não chega a altos patamares.

Consideramos que no caso das sociedades estudadas o conceito de racismo apresentado por Wallerstein (WALLERSTEIN in MACHADO, 2000) é também extremamente oportuno. Para ele, o racismo é a 'fórmula mágica' que favorece os objetivos de maximização da acumulação do capital, ao mesmo tempo em que minimiza os custos que ela implica.

Estamos de acordo com Diana Brydon e Helen Tiffin (1993) quando afirmam que nossas mentes, assim como nossas economias, precisam ser 
descolonizadas, isto porque, os países que são oficialmente independentes ainda sofrem pressões econômicas e psicológicas da dependência. Hoje, inseridos na conhecida sociedade do saber, do instantâneo (dos e-mails, aviões, I-pods, internet etc.), é possível que a língua inglesa seja o instrumento de libertação tanto de brasileiros, como de canadenses franceses e não nos esqueçamos dos moçambicanos, ilhados na anglofonia da África Meridional.

Para que tenhamos o domínio desta ferramenta, mais uma vez teremos que recorrer à escola. Não a escola reprodutora, aquela que favorece os mais favorecidos conforme explicitamos, especialmente, em 3.1, 3.2 e 3.3, mas uma escola de democratização do saber, desde que

[....] ela não consagrasse, ignorando-as, as desigualdades iniciais diante da cultura e se ela não chegassse freqüentemente - censurando por exemplo a um trabalho escolar por ser muito 'escolar' - a desvalorizar a cultura que ela transmite' em proveito da cultura herdada, que não traz a marca plebéia do esforço e tem, por essa razão, todas as aparências da facilidade e da graça (BOURDIEU, 1964, p. 35).

Sendo assim, a Lei Lei 10639/03 e suas decorrências, no Brasil; e a Lei de Quebec Révolution tranquille; a Charter of Rights and Freedoms accommodement raisonnable, no Canadá, estão de acordo com o que afirmou Fanon:

É preciso que ordenemos todos os atos desesperados de descolonização de nossas mentes, de nossos gostos, hábitos e veneração pela cultura da metrópole.

Há que se admirar e cantar como nação [....] para garantir a salvação, para escapar à supremacia cultural branca, o colonizado sente a necessidade de retomar a raízes ignoradas, de perder-se, aconteça o que acontecer [.... (FANON, 2002, p. 246 e 250).

De um modo geral, afirmamos que há necessidade de se efetuar mais pesquisas a respeito dos determinantes do salário e do capital humano e o papel desempenhado pela escola frente ao racismo e à desconstrução do 
mesmo (ESSED, 2000) tanto no Brasil como no Canadá, conhecidas como sociedades que atraem imigrantes de diversas partes do planeta e abrigam pessoas de diferentes origens étnicas, sociais e religiosas.

\section{Referências bibliográficas}

MACHADO, F. L.. Os novos nomes do racismo: especificação ou inflação conceptual?, Problemas e Práticas, nº 33, p. 9 a 44, 2000.

BHABHA, H. K. . O local da cultura. Belo Horizonte: UFMG, 2005. In: SANTOS, B. S.. A gramática do tempo: para uma nova cultura política. Porto: Afrontamento, 2005.

BOURDIEU, P.; CHAMPAGNE, P.. Os excluídos do interior. In: BOURDIEU, P. (Org.).

BOURDIEU, P.. Le racisme de l'intelligence. Questions de Sociologie. Paris: Les Éditions de Minuit, 1980.

Escritos de educação. Petrópolis: Vozes, 1998.

- A miséria do mundo. Petrópolis: Rio de Janeiro: Vozes, 2001.

PASSERON, J.. Les héritiers: Les étudiants et la culture. Paris:

Minuit, 1964.

BRASIL. Lei 10.639, de 9 de janeiro de 2003, que estabelece as Diretrizes e Bases da Educação Nacional, para incluir no currículo oficial da rede de ensino a obrigatoriedade da temática história e cultura afro-brasileira e indígena. Disponível em: < http://www.planalto.gov.br/ccivil_03/_Ato20072010/2008/Lei/L11645.htm >. Acesso em 2 maio 2010.

BRYDON, D.; TIFFIN, H.. Decolonising fictions. Sydney: Dangaroo, 1993.

CATTANI, A. D. Desigualdades socioeconômicas Brasil/Canadá: um estudo a partir dos extremos. Interfaces Brasil/Canadá, Rio Grande, FURG-ABECAN, n. 6, 2006. Disponível em: http://www.revistabecan.com.br/arquivos/1157676973.pdf. Acessado em: 16 set. 2010. 
CHEVALLARD, Y. La transposition didactique: du savoir savant au savoir enseigné. Paris: Ed. La Penseé Sauvage, 1991.

CORMIER, M.. La pédagogie en milieu minoritaire francophone: une recension des écrits. Université de Moncton pour l'Institute canadien de recherche sur les minorités linguistiques commandé para la Fédération canadienne des enseignantes et des enseignants, 2005.

DIJK, T. van. Communicating racism: ethnic prejudice. Thought and Talk. In: MACHADO, F. L.. Os novos nomes do racismo: Especificação ou inflação conceptual?, Problemas e Práticas, n³ 33, p. 9 a 44, 2000.

ELBAZ, M.; D., H.. Mondialisation, citoyenneté et multiculturalisme. Québec: Les Presses de l'Université Laval, 2000.

ESSED, P.. Understanding everyday racism: an interdisciplinary theory In: MACHADO, F. L.. Os novos nomes do racismo: Especificação ou inflação conceptual?, Problemas e Práticas, nº 33, p. 9 a 44, 2000.

EUSÉBIO, J.. Falando português em Montreal. Montreal: Quebec World, 2001.

FANON, F.. Os condenados da terra. Minas Gerais: Editora da UFJF, 2002.

HELLY, D.. Le Québec face à la pluralité culturelle 1977-1994. Un bilan documentaire des politiques. Québec: Les Presses de l'Université Lavál et Institut québécois de recherche sur la culture, 1996.

KANOUTÉ,-F...Profils d'acculturation d'élèves issus dé l'immigration récente à Montréal. Revue des Sciences de I'Education, v. 28, n. 1, p. 171190, 2002.

MACHADO, F. L.. Os novos nomes do racismo: especificação ou inflação conceptual?, Problemas e Práticas, nº 33, p. 9 a 44, 2000.

RIFFEL, J. A.; LEVIN, B.. Dealing with diversity: some propositions from Canadian education. University of Manitoba. Disponível em: <http://epaa.asu.edu/epaa/v2n2.html>. Acesso em: 11 set. 2006.

ROCHA-TRINDADE, M. B.. The portuguese Diaspora. In: TEIXEIRA, C. and DA ROSA, V. P. (Eds.). The portuguese in Canada: from the sea to the city. Toronto: University of Toronto Press, p. 15-33, 2000. 
SANTOS, B. S.. A gramática do tempo: para uma nova cultura política. Porto: Afrontamento, 2005.

TAGUIEFF, P.. La Force du Préjugé: essai sur le racisme et ses doubles. In: MACHADO, F. L.. Os novos nomes do racismo: Especificação ou inflação conceptual?, Problemas e Práticas, nº 33, p. 9 a 44, 2000.

Les métamorphoses idéologiques du racisme et la crise. In: MACHADO, F. L.. Os novos nomes do racismo: Especificação ou inflação conceptual?, Problemas e Práticas, no 33, p. 9 a 44, 2000.

TEIXEIRA, C.. On the move: portuguese in Toronto. In: TEIXEIRA, C. da ROSA, V. P. (Eds.). The portuguese in Canada: From the Sea to the City. Toronto: University of Toronto Press, p. 207 - 220, 2000.

VIERIA, A. B.. Racismo e teoria. In: MACHADO, F. L. (2000); Os nolvos nomes do racismo: especificação ou inflação conceptual?, Problemas e Práticas, nº 33, p. 9 a 44, 2000.

WALLERSTEIN, I.. Le capitalisme historique. Paris, Editions La Découverte, 1987.

Capitalismo histórico e civilização capitalista. Rio de Janeiro: Editora Contraponto, 2001.

Os Estados Unidos e o mundo: as Torres Gêmeas como metáfora, ESTUDOS AVANÇADOS 16 (46), 2002a.

. Os Estados Unidos em declínio? In: WALLERSTEIN, I. M.. O fim

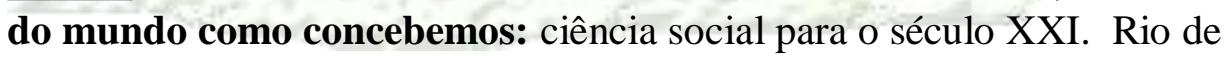
Janeiro: Revan, 2002b.

Universalisme, racisme, sexisme: les tensions ideologiques du capitalisme. In: BALIBAR, É. ; WALLERSTEIN, I.. Race, nation, classe: les Identités Ambiguës, Paris, Éditions La Découverte, 1988. 


\begin{abstract}
Autora:
Nilce da Silva

Profa. Dra. da Faculdade de Educação da Universidade de São Paulo e pesquisadora regular da Université du Québec à Trois-Rivières.

Contato: nilce@usp.br
\end{abstract}

Artigo recebido em agosto de 2010.

Artigo aprovado para publicação em março de 2011.

\title{
Como citar este texto:
}

SILVA, N. da. Tentativas de desconstrução do racismo e preconceitos: um diálogo entre o Norte e o Sul do no século XXI. Revista Acolhendo a Alfabetização nos Países de Língua Portuguesa, Brasil, São Paulo, volume 1, no. 10, pp. 123 - 145, Mar. 2011. Disponível em: <http://www.acoalfaplp.net>. 